\title{
INTERPRETANDO O LUGAR DA EDUCAÇÃO FÍSICA ESCOLAR NA "CULTURA DE VIOLÊNCIAS": NOTAS DE UMA ETNOGRAFIA.
}

\author{
Gabriel Gules Goularte \\ Universidade Federal do Rio Grande do Sul, Porto Alegre, Rio Grande do Sul, Brasil. \\ Fabiano Bossle \\ Universidade Federal do Rio Grande do Sul, Porto Alegre, Rio Grande do Sul, Brasil. \\ Tiago Nunes Medeiros \\ Universidade Federal do Rio Grande do Sul, Porto Alegre, Rio Grande do Sul, Brasil. \\ Leandro Oliveira Rocha \\ Universidade Federal do Rio Grande do Sul, Porto Alegre, Rio Grande do Sul, Brasil.
}

\begin{abstract}
Resumo
Como objetivo central de estudo, o presente artigo busca compreender o lugar da Educação Física escolar no contexto das violências em duas escolas da rede pública de um município do Rio Grande do Sul. Para tanto, ampara-se na perspectiva teórico-metodológico de uma etnografia realizada nos anos de 2013, 2014 e 2015. O fenômeno do tráfico de drogas e o desfavorecimento social são marcadores significativos do que é compartilhado no interior das escolas. Fato que traz implicações no trato com as manifestações da cultura corporal de movimento no cotidiano da Educação Física escolar singular para a qual buscamos a interpretação.
\end{abstract}

Palavras-chave: Educação Física Escolar. Violências. Etnografia.

\section{INTERPRETING THE PLACE OF SCHOOL PHYSICAL EDUCATION IN THE "CULTURE OF VIOLENCE": NOTES OF AN ETHNOGRAPHY.}

\begin{abstract}
As a central objective of this study, this article seeks to understand the place of Physical School Education in the context of violence in two schools of the public network of a municipality of Rio Grande do Sul. Therefore, it is based on the theoretical and methodological perspective of ethnography in the years of 2013, 2014 and 2015. The phenomenon of drug trafficking and social disadvantage is significant markers of what is shared within schools. This fact has implications in dealing with the manifestations of the body's movement culture in the daily life of Physical School Education for which we seek interpretation.
\end{abstract}

Keywords: Physical School Education. Violence. Ethnography. 


\title{
INTERPRETANDO EL LUGAR DE LA EDUCACIÓN FÍSICA ESCOLAR EN LA "CULTURA DE VIOLENCIAS": NOTAS DE UNA ETNOGRAFÍA.
}

\begin{abstract}
Resumen
Como objetivo central del estudio, este artículo busca comprender el lugar de la educación física escolar en el contexto de la violencia en dos escuelas públicas de una ciudad de Rio Grande do Sul. Por lo tanto, se basa en la perspectiva teórico-metodológica de una etnografía realizada en 2013, 2014 y 2015. El fenómeno del narcotráfico y la desventaja social son marcadores significativos de lo que se comparte dentro de las escuelas. Este hecho tiene implicaciones en el tratamiento de las manifestaciones de la cultura corporal del movimiento en la rutina diaria de la educación física escolar única para la que buscamos interpretación.
\end{abstract}

Palabras-clave: Educación Física Escolar. Violencia. Etnografía.

\section{Introdução}

Ao sugerirmos o entendimento da educação a partir da perspectiva de um processo compartilhado entre diferentes sujeitos e instituições sociais, nos parece plausível propor uma necessária imersão na observação e interpretação das relações microscópicas ocorridas em contextos marcadamente influenciados por uma correlação de forças que neles incidem e se legitimam. Amparados pela perspectiva da pedagogia crítica, entendemos importante destacar que se a escolarização pode estar relacionada a uma forma de controle social, a educação pode configurar uma potente ferramenta de transformação social, uma vez que esteja empenhada em contribuir para o desenvolvimento do aluno como sujeito crítico e ativo (MCLAREN,1997).

Embasado por essas reflexões, ao analisarmos a contextualização da instituição escolar, reconhecemos indícios suficientes para a percepção de episódios de desestabilização nesse potente cenário de fomento educativo, de ensino, aprendizagens e formação humana (BOSSLE, MOLINA NETO, WITTIZORECKI, 2013; DEBARBIEUX, 2002; SOARES, 2013; SPOSITO, 2001). Ao entendermos, na contemporaneidade, a contextualização da instituição escolar como "parte do tecido social e político existente que caracteriza a sociedade dominante" (MCLAREN, 1997, p. 191), sugerimos a análise da rede de relações e das forças que nela operam. Assim, julgamos importante discutir sobre as implicações que essas interferências criam na escola justamente a partir de um contexto de mudanças (sociais, econômicas, políticas, culturais, dentre outras), reconhecendo o processo de mercantilização comum a esse período, estendendo seus domínios também para o campo da educação em uma consequente despolitização das instituições públicas (APPLE, 2005) ${ }^{1}$.

Assim, na busca por compreender como a temática das violências tem sido percebida no contexto escolar e, mais especificamente, na perspectiva da Educação Física, o presente trabalho propõe um recorte analítico e reflexivo de uma etnografia (WOODS, 1998; GEERTZ, 2008) realizada na perspectiva de uma opção teórico-metodológica potente para compreender os aspectos simbólicos da cultura compartilhada pelas comunidades escolares de duas instituições de ensino da Rede Municipal de Gravataí/RS com as violências.

Nossa opção se sustenta ainda no que Marcus (1998) sugere: "os termos da análise propriamente etnográfica devem ser contestados e reconstruídos 'do chão para cima'" (MARCUS, 1998, p. 40), ou seja, entendemos que no esforço do trabalho de campo são produzidas as experiências interpretativas articuladas pelo nexo entre o local e global. Dessa ma-

\footnotetext{
${ }^{1}$ Tomando como referência a opção de se discutir os efeitos da globalização a partir de Castells (1999), Bauman (2001) e Santos (2001). 
neira, o planejamento do estudo se fez pautado a partir de uma concepção processual da etnografia, compreendendo sua perspectiva teórico-metodológica como uma prática "artesanal, microscópica e detalhista" (PEIRANO, 1995, p. 57). E, para tanto, o objetivo delimitado para este artigo foi compreender o lugar da Educação Física escolar no contexto das violências em duas escolas da Rede Municipal de Ensino de Gravataí.

\section{O trabalho de campo e as interpretações da etnografia}

A opção teórico-metodológica pela etnografia é pautada pelo entendimento de que o fenômeno de pesquisa está circunscrito ao universo simbólico da cultura. Duas escolas municipais foram elencadas para realização da etnografia na cidade de Gravataí/RS, as quais denominamos EMEF AA e EMEF RM, nomes esses fictícios, empregados a fim de conferir sigilo na identificação das instituições de ensino. Iniciado em novembro de 2013 a partir dos primeiros contatos junto à Secretaria Municipal de Educação de Gravataí/RS e, posteriormente, retomados em março de 2014, com o início do ano letivo nas escolas municipais, o trabalho de campo teve a duração de um ano letivo.

Como participantes do estudo foram definidos os três professores de Educação Física das instituições pesquisadas, bem como membros das equipes diretivas. No que envolve os cuidados éticos empregados pelo estudo, bem como a busca pela garantia de que a validade das interpretações produzidas fosse efetivada, foi realizada a devolução das entrevistas com os participantes do estudo a fim de que pudessem propor correções e/ou ajustes em suas falas, além da autorização dos participantes para utilizá-las como material de pesquisa, quesito contemplado por meio da apresentação e assinatura dos Termos de Consentimento Livre e Esclarecido $^{2}$. Além disso, ao término do estudo, foram disponibilizadas cópias do relatório final produzido para as duas escolas investigadas.

Já em relação aos instrumentos de coleta de informações, foram utilizadas as observações dos participantes, diários de campo, diálogos, entrevistas semiestruturadas, além da coleta e análise de documentos. Desse modo, 70 observações foram realizadas, sendo 32 na escola EMEF RM e 33 na escola EMEF AA, totalizando 144 horas e 55 minutos.

Nesse ponto, destacamos a árdua tarefa de significar relações, observando minuciosamente detalhes e nuances em um empreendimento que busca compreender a ocorrência desta teia de relações no compartilhar cultural investigado. Para Zaluar (1986), a primeira grande armadilha do trabalho de campo etnográfico estaria no menosprezo da riqueza de significados que as ações, práticas, símbolos, ritos, conversas informais, dentre outros signos carregam para a interpretação de culturas distintas em sua essência e constituição. Assim, a etnografia empreendida se constituiu como um mosaico de informações, métodos, pistas, escolhas, conflitos, estranhamentos, simbolismos, objetividades e subjetividades que, uma a uma, são conjecturadas na interpretação do trabalho de campo.

\section{Resultados e discussão: os achados da investigação e interpretação das violências envol- vidas com o contexto escolar}

Ao nos debruçarmos na reflexão sobre a etnografia realizada, parece-nos importante retornar e retomar exatamente o objetivo central do estudo, apresentado a partir da seguinte formulação: compreender o lugar da Educação Física escolar no contexto das violências em duas escolas da Rede Municipal de Ensino de Gravataí.

Ao planejar a pesquisa em escolas situadas em contextos envolvidos por violências, pensamos estar imergindo em ambientes escolares diretamente envolvidos com episódios de

\footnotetext{
${ }^{2}$ Em acordo com as diretrizes da resolução 466/12 do Conselho Nacional de Saúde.
} 
brigas e agressões verbais, violentos em sua própria constituição. Entretanto, a realidade se mostrou diferente. Estabelecemos esse apontamento por conceber a etnografia enquanto um caminho pelo qual as aprendizagens são construídas conforme a imersão em contextos e realidades que se predispõe estudar e, nesse sentido, o trabalho de campo se potencializa como promotor de apontamentos e reflexões para os fenômenos inquiridos.

Revisitando os elementos e informações obtidos a partir do trabalho de campo, tornaram-se significativas as representações simbólicas de violências manifestadas na convivência com as duas escolas investigadas. E, por esse motivo, acreditamos que as manifestações dessas violências simbólicas (citamos a precarização das condições físico-estruturais; instauração de movimentos grevistas em função da melhoria de salários para os docentes; aumento, acúmulo e intensificação das tarefas destinadas aos professores), representaram o agravamento de uma situação crítica vivenciada pelos docentes e pelas comunidades nas escolas. Exemplos do entrelaçamento dessas condições de precarização do trabalho docente se fazem presentes nas passagens dos diários de campo apresentados a seguir, tanto nos espaços de aula (ou falta de espaço), quanto nas diferentes ações dos professores em sua prática cotidiana.

Acompanho a profa. Vilma até a quadra de esportes. Subimos a rampa que possibilita o acesso de cadeirantes e, ao acessar a quadra, ela conta: "como tu vê, a quadra é de chão batido, então quando chove tem erosão", mas complementa "ainda assim fomos campeões dos Jogos Municipais Escolares no ano passado no vôlei”. (Diário de campo, observação 8, EMEF AA, 3/4/2014).

Então não adianta falar que está aqui só para ensinar, está aqui só para educar. Nessa comunidade tu tem que educar assim, tu tem que muitas vezes dizer para ele "olha meu filho, tu tem que ir no banheiro e puxar a descarga, tu tem que ir no banheiro e pegar papel higiênico", porque muitos não têm isso em casa [...]. Porque assim ó, às vezes, parece que todo mundo é igual, mas daí tu vê que não é, que tem criança que não tem banheiro. Tem criança ali que não tem uma cama para dormir, dorme amontoado no sofá. (Márcia, diretora escola RM, entrevista realizada em 17/11/2014).

Embora reconheçamos a dificuldade em se definir um conceito único ou categorizações para o termo, uma vez identificada a proximidade das escolas com episódios violentos e sugeridas as possíveis representações acerca da materialização de fenômenos dessa natureza nas duas instituições de ensino, o passo seguinte proposto pelo estudo foi o de compreender como se estabelecia o compartilhamento das culturas entre os sujeitos relacionados com as escolas. Ou seja, de que forma as relações com as violências presentes naqueles dois contextos singulares interferiam e repercutiam no trabalho docente e no próprio cenário escolar.

Para isso, buscamos interpretar a concepção dos professores de Educação Física e membros das equipes diretivas para a convivência das instituições escolares com as realidades particulares em que estão inseridas. Levando em consideração esses achados, apontamos para a íntima proximidade com o tráfico de drogas ilícitas, que ocorre nos dois bairros em que as EMEF AA e RM estão abrigadas, como um dos indicadores principais das violências ali instituídas que destacamos no fragmento do diário de campo a seguir:

O tráfico de drogas aqui é muito grande e não se consegue eliminar, a polícia tira um, daí vêm dois ou três. Nós temos uma invasão agora com 240 famílias. Então o principal fator da violência é o tráfico de drogas e daí depois vem a agressão familiar, o pai que bebe, mas está tudo envolvido com drogas, tem ali o álcool, tem a cocaína, o crack. A pedra de crack tomou conta. Maconha é cigarro hoje em dia. (Letícia, coordenadora pedagógica, EMEFAA, entrevista realizada em 15/12/2014).

Essa identificação das repercussões dos enlaces envolvidos com o tráfico foi compreendida já nas primeiras observações de campo. Constatamos que as relações das escolas com 
as violências não poderiam ser estabelecidas levando em consideração apenas o que ocorria em seus espaços físicos (violências com origem dentro da escola exclusivamente). Era necessário relacionar também os compromissos formais da educação escolarizada com as realidades particulares em cada contexto. E assim, destacamos duas passagens em que é possível identificar essa relação próxima da convivência das escolas com episódios de violências que, embora não fossem deflagrados em de seus espaços físicos, estendiam-se para dentro deles como um prolongamento do contexto social compartilhado no bairro:

Para a Orientadora Pedagógica, o aspecto da violência está "muito próximo dos alunos". Ao afirmar isso, ela cita como exemplo a conversa que a diretora teve com um policial da brigada militar na noite anterior (vale lembrar que no turno da noite a escola recebe turmas de EJA): "para nossa segurança, o policial disse para que não buscássemos nos aprofundar nessas relações de brigas entre gangues que existem no bairro". (Diário de campo, observação 1, EMEF RM, 7/3/2014).

Pergunto sobre a incidência de furtos e Catia diz que é quase a $10^{\circ}$ vez no ano que "entram" na escola. "Só falta entrarem na direção", em referência ao fato de que na sala da direção existem computadores, além da TV de LCD utilizada pela escola. Acompanho a Supervisora até a sala da direção e no caminho ela conta "Gabriel, é difícil! Sabemos de muitos alunos que estão envolvidos com tráfico. Hoje mesmo, dois que estavam no portão conversando com outros meninos na rua, eu sei que estão no tráfico". Ela se refere a dois adolescentes que no recreio conversavam com outros três adolescentes na grade da escola. "É bem complicado. Mas a gente vai tentando fazer a nossa parte" e logo ela pede licença, seguindo para a sala da direção. (Diário de campo, observação 25, EMEF AA, 29/7/2014).

Apontamos assim indícios do quanto os fatores externos ao ambiente escolar adentravam e influenciavam as relações estabelecidas dentro das instituições. A questão do controle do tráfico de drogas nos bairros em que as escolas estão inseridas foram assim pontos comuns às duas instituições. Professores e membros das equipes diretivas também precisavam lidar com situações ocorridas além dos muros das escolas, mas (re)conhecidas por eles, para a construção de suas práticas pedagógicas rotineiras, ressignificadas a partir das concepções pedagógicas dos professores e de seus percursos profissionais particulares.

Inerente a isso, o aspecto do desfavorecimento social também se configurava como fator das violências com as quais ambas as escolas passam a conviver em seu cotidiano:

Eu entendia a violência como agressão mesmo, como a questão física. Só que eu noto que a violência de negligência é muito maior. Ela é muito maior e é invisível. E a gente aceita e ensina ela. Então, eu tenho alunos que sofrem violências muito grandes, mas que são resilientes sobre elas, mas não resilientes sobre a negligência. Toda a questão de como eles são vistos no bairro, de eles não saírem do bairro, essa é a maior violência. Então hoje eu trato violência assim: como sofrimento. (André, professor de Educação Física, EMEF RM, entrevista realizada em 1/12/2014).

Ao compreender as mudanças sociais como interferentes também nas condições de bem-estar (ou mal-estar) dos sujeitos frente às adaptações impostas pelos processos de modernidade, Esteve (1999) reconhece na escola um dos inevitáveis locais influenciados pelo turbilhão de mudanças decorrente de uma realidade multifacetada. Para o autor, essas tensões de que padecem os professores geram um descontentamento entre os docentes, haja vista 0 paradoxo de que a mesma sociedade que exige dos professores novas responsabilidades, não lhes fornece alternativas para cumprir essas exigências.

Olha, eu acho assim, apesar de o bairro ser considerado violento, eu acho que tem muita gente boa aqui e acho que, às vezes, até a gente comete violência com a criança dentro da própria escola. No momento que a gente já olha para ele com outro o- 
lhar por ele fazer parte daquele bairro, no momento que a gente fala "ah, ele é filho do fulaninho". E acho que, assim, não é apenas porque o pai ou mãe é traficante que eles serão violentos. Claro, eles levam isso para dentro da escola. E acho que isso também tem que cuidar enquanto professor. Eu também acho que é uma violência assim, ele estar ali quietinho e tu não dar bola, mas tu vai a fundo pesquisar, o que aquela criança sofre, é a falta de comida, é a fome, é a mãe que não tá nem aí com ele, não é só pegar revólver. Eles sofrem com o mundo, é uma violência contra o ser humano mesmo, contra a dignidade deles. (Márcia, entrevista realizada no dia $17 / 11 / 2014)$.

Diante dessa realidade, professores e equipes diretivas citaram em diálogos ocorridos ao longo do período investigativo a importância da compreensão de seus papéis a fim de se evitar a reprodução simbólica das violências causadas pelas mazelas sociais que os alunos e moradores do bairro estavam expostos. E aqui, destacamos o posicionamento do professor André quando admite a dificuldade do estabelecimento do sujeito professor em um contexto configurado por situações de múltiplas violências. Quando perguntado sobre como ele entendia sua posição como professor de Educação Física em uma realidade estabelecida a partir da convivência com episódios de guerra entre gangues, violências familiares e, sobretudo, exclusão social, André afirmou:

Essa conclusão sobre sujeito e professor aqui é muito complicado. [...]. Não é algo romântico. Ou é algo romântico no estilo dramático de ser. E isso é meu, é o que eu estou sentindo agora. Não é algo pensado, refletido por muito tempo e articulado em um papel e revisto. Esse é meu sentimento de agora, minha informação de agora. E não tem receita, não tem mecanismo, mas é algo que vai te sugar. A demanda vai te sugar mentalmente. Então saber lidar com toda essa situação é delicado e não é só a relação profissional, há um sujeito que veste essa roupa de professor de Educação Física. (André, entrevista realizada no dia 1/12/2014).

Diante disso, esses foram os dois indicadores interpretados junto às duas instituições de ensino no que envolve o fenômeno investigado: desfavorecimento social e o tráfico de drogas ilícitas. Inevitavelmente, todos os prolongamentos desses indicadores repercutiam nos processos de escolarização propostos pelas instituições de ensino e, de modo mais específico, no componente curricular Educação Física, alvo do presente artigo.

E assim, pensando na construção analítica que nos permitiu caracterizar a configuração do componente curricular Educação Física nas duas escolas públicas municipais de Gravataí estudadas, apontamos aspectos que entendemos além do trabalho realizado em classe pelos professores da disciplina. Dito isso, buscamos discutir os efeitos simbólicos e visíveis causados pela precarização do ensino público que expuseram a realidade de falta de salas de aula, terrenos de chão batidos transformados em quadras de esportes, acúmulo de disciplinas por professores sem formações específicas em uma determinada área, faltas e atrasos de docentes, dentre outros, como a dupla docência exercida pelo professor André durante o ano letivo de 2014, retratada no diálogo registrado no diário de campo da seguinte maneira:

"Eu tenho três manhãs no colégio e outra para planejar, mas o planejamento não é feito na escola". Além disso, André comentou: "Tem o fato de sermos quebra-galho muitas vezes. Por exemplo, nesse ano leciono Artes também. Ainda bem, porque é melhor que Religião". (André, Diário de campo, observação 26, EMEF RM, 26/7/2014).

Outro exemplo de precarização, no caso da EMEF AA, é o espaço utilizado como quadra de esporte, em que, em alguns turnos escolares, era dividido por mais de uma turma de alunos. Nesses momentos, as docentes estabeleciam o compartilhamento do espaço, seja a partir da separação da quadra em setores que acomodassem todas as turmas, seja empregando 
os jogos coletivos entre as turmas que tinham aula no momento, como aponta o seguinte fragmento:

\begin{abstract}
Por volta de 9h30, percebo os alunos do Programa "Mais Educação" também acessando o espaço e se posicionado onde Fátima (professora sem formação em EF) havia começado sua aula, no canto do terreno onde está a quadra, ainda embaixo da sombra dos eucaliptos. Dessa maneira, durante pouco mais de 30 minutos, o espaço onde ocorrem as aulas de Educação Física acaba sendo divido por 4 turmas de alunos de faixas etárias distintas ( 2 turmas com a professora Vilma, 1 turma com a professora Fátima e 1 turma com a professora do Programa Mais Educação). Os alunos do "Mais Educação", estudantes do turno da tarde e, portanto, até o $5^{\circ}$ ano do ensino fundamental, realizam estafetas e brincadeiras recreativas. Já as turmas com as professoras Vilma e Fátima permanecem entre jogos de futsal, na maior parte do tempo com os meninos jogando, além do slackline. Muitos alunos ficam sentados pelo espaço da quadra. (Diário de campo, observação 45, EMEF AA, 7/10/2014).
\end{abstract}

Passo seguinte, no que tange especificamente ao trabalho em classe, no caso da EMEF AA, interpretamos a disciplina empregando o esporte como meio de reforçar os vínculos da convivência social pautada pelo respeito às regras inerentes ao trabalho com modalidades esportivas. Essa visão é compartilhada pelas professoras para esse componente curricular da escola, ainda que residisse nessa opção a centralidade do papel desempenhado pelos docentes na definição dos conteúdos e abordagens pedagógicas, ou seja, não necessariamente a partir de uma construção coletiva.

É que, assim, os alunos acabavam querendo só futsal e nós tínhamos, como proposta da escola, trabalhar três ou quatro esportes. Como a gente tem uma quadra precária, o basquete não pode ser incluído, então optamos pelo vôlei no primeiro trimestre, daí montamos a quadra lá em cima, no segundo trimestre o handebol porque mesmo precariamente a gente consegue fazer e no terceiro trimestre o futsal, que é o que eles mais gostam de fazer. (Vilma, professora Educação Física, EMEFAA, entrevista realizada em 11/12/2014).

Na EMEF RM, a centralidade no aluno como protagonista na construção das aprendizagens era configurada a partir de proposições pedagógicas que evidenciavam a intenção do docente em romper com práticas ou abordagens únicas e excludentes de outras vertentes da constituição histórica da Educação Física como componente curricular, aproximando o planejamento da disciplina à discussão crítica sobre a realidade vivida e vivenciada pelos alunos. Quando questionado sobre a forma como define os conteúdos abordados na EMEF RM, o professor explicou:

Eles variam de acordo com a ideologia da Educação Física e acho que este é o maior trabalho, ou seja, de criar blocos de conteúdo, de criar uma sistemática e de "quebrar" (romper) ele. E esse é o maior conflito. Eu tenho uma programação do bloco de conteúdo, mas eu preciso de um espaço que seja mais livre, que eu vá por onde eles precisam. Terapias corporais, jogos cooperativos, enfim. E depois colocar jogos competitivos para ver como eles vão conviver com a competição. (André, professor de Educação Física, EMEF RM, entrevista realizada em 1/12/2014).

Com isso, esperamos brevemente ter percorrido o caminho que nos permitirá delinear o que se propõe o seguinte estudo: reconhecer o espaço da Educação Física nestes contextos envoltos por violências de diferentes ordens. Nessa composição percebemos cristalinamente uma construção pautada pela adequação da disciplina escolar a partir do reconhecimento das particularidades que tocam as escolas nos seus cotidianos, bem como a partir das convicções e perspectivas pedagógicas dos professores. 
Sustentado o planejamento, aproximação e permanência em campo durante o período da etnografia, dúvidas e inquietudes se desfizeram, ao passo que novos questionamentos brotavam com o objetivo de compreender o compartilhar das práticas sociais presentes nos dois contextos de pesquisa. Estando dentro da escola, pudemos perceber a complexa teia de relações que estabelece a constituição singular de cada instituição de ensino. No caso do estudo, entendemos que o espaço da Educação Física nas escolas esteve diretamente associado aos arranjos dos diferentes fatores nela interferentes (sujeitos envolvidos, concepções para o componente curricular, momento histórico, culturas compartilhadas e outros possíveis) sob os quais buscamos a interpretação na etapa que segue.

\section{Conclusões}

Consideramos relevante retomar o objetivo do artigo, de modo a manter alinhadas nossas considerações finais: compreender o lugar da Educação Física escolar no contexto das violências em duas escolas da Rede Municipal de Ensino de Gravataí. A cultura de violências a que estão submetidas as escolas onde a etnografia foi realizada, em nosso entendimento, constitui-se de maneira cristalizada nas relações sociais estabelecidas na instituição escolar. Não raramente, elas vão deslocando a sua função social para o trato simplificador - e não menos importante - do enfrentamento de questões mais urgentes e, menos, para o trato e aprofundamento do processo de ensino-aprendizagem compartilhado com a cultura escolar nacional e previsto nas diretrizes curriculares e marcos legais.

Com isso, nossas interpretações sobre as referidas culturas escolares remetem à compreensão de que há muitos sentimentos e carências envolvidas e fortemente significadas nas práticas sociais compartilhadas e uma perspectiva "apocalíptica" e pessimista no sentido de produção no campo das possibilidades, seja nas políticas públicas, seja no Estado, seja na escola ou na humanidade. Foi justamente a partir dessa compreensão que tencionamos entre os aspectos simbólicos manifestos nas relações de ordem macro e microssociais, nos quais percebemos, portanto, as violências como fenômenos correlatos à configuração do cenário moderno a partir de diferentes variáveis.

Imbuídos pela intenção de melhor compreender as violências envolvidas no contexto escolar, diante do componente curricular Educação Física e tais características, dentro das escolas AA e RM foi possível perceber a teia de relações que estabeleceram uma manifestação e representação singular para cada instituição de ensino. A partir dos elementos e informações obtidos com o trabalho de campo, acompanhamos as representações simbólicas se constituindo como principal faceta das violências com as quais as escolas estão em contato, desvelando detalhes da precarização das condições físico-estruturais das instituições escolares, bem como o aumento, acúmulo e intensificação das tarefas destinadas aos professores.

Levando em consideração esses achados, apontamos a íntima proximidade com o tráfico de drogas ilícitas ocorrida nos dois bairros em que as escolas AA e RM estão abrigadas, um dos indicadores principais para as violências ali instituídas. Inerente a isso, o aspecto do desfavorecimento social também se configurava como impactante nas violências com as quais ambas as escolas passavam a conviver em seu cotidiano.

Nesse ponto, podemos constatar que as aulas de Educação Física são espaços organizados pelos professores a fim de abrigar diferentes culturas que se intercruzam e que, por certo, produziam novos arranjos. Portanto, era inevitável que os fatores ligados às múltiplas faces das violências, comuns aos dois contextos, repercutissem nos processos de escolarização e práticas pedagógicas propostas pelos professores. Isso se verifica nas condições de precarização do ensino público (falta de quadras esportivas e salas de aula, diferentes turmas escolares dividindo o mesmo espaço de aula, dentre outros), e também nas alternativas buscadas pelos professores para contemplar as demandas do componente curricular. 
Nesse sentido, o que na pesquisa nos referimos como relacionado ao trabalho em classe, no caso da EMEF AA, vimos a utilização do esporte como meio de reforçar os vínculos da convivência social, pautado pelo respeito às regras inerentes ao trabalho com modalidades esportivas, bem como a partir da intenção de reconhecimento de outras realidades sociais a partir das saídas para jogos e competições escolares. Embora possamos tecer uma crítica à centralidade do papel desempenhado pelos docentes na definição dos conteúdos e abordagens pedagógicas. Na EMEF RM, a busca pela centralidade no aluno na construção das aprendizagens foi sistematizada a partir de blocos de conteúdos que evidenciavam a intenção do docente em se valer de diferentes abordagens didáticas e pedagógicas, aproximando o planejamento da disciplina à discussão crítica sobre a realidade vivida pelos alunos.

Ao fim destacamos a nossa compreensão sobre o local ocupado pela Educação Física: o esforço, a partir de diferentes concepções dos professores investigados sobre o componente e as realidades particulares das culturas escolares, para as relações socioculturais ali representadas. Percorrendo, para isso, uma via de mão dupla que perfizesse o caminho a partir da relação macroanalítica de como as diversas culturas circundantes e intercambiadas incidiram nas culturas escolares. Ao passo que investigamos também nas aulas de Educação Física as diferentes formas como as culturas escolares e a cultura corporal de movimento desenvolvidas nas aulas se organizavam e buscavam garantir sentido e significado a suas práticas.

\section{Referências}

APPLE, M. Para além da lógica de mercado: compreendendo e opondo-se ao neoliberalismo. Rio de Janeiro: DP\&A, 2005.

BAUMAN, Z. Modernidade líquida. Rio de Janeiro: Jorge Zahar, 2001.

BOSSLE, F.; MOLINA NETO, V.; WITTIZORECKI, E. “A vida como ela é”: os professores de Educação Física e as violências na escola pública de Porto Alegre. Movimento, Porto Alegre, v. 19, n.4, p. 47-67, out./dez. 2013.

CASTELLS, M. A sociedade em rede - a era da informação: economia, sociedade e cultura. São Paulo: Paz e Terra, 1999.

DEBARBIEUX, E. Violências nas escolas: divergências sobre palavras e um desafio político. In: DEBARBIEUX, E.; BLAYA, C. (org.). Violência nas escolas e políticas

públicas. Brasília: UNESCO, 2002. p. 59-87.

ESTEVE, J. M. Mudanças sociais e função docente. In: NÓVOA, António (org.). Profissão professor. Porto: Porto Editora, 1999. p. 63-124.

GEERTZ, C. A interpretação das culturas. 1. ed. 13. reimp. Rio de Janeiro: LTC, 2008.

MARCUS, G. Ethnography Through Thick and Thin. Princeton: University Press, 1998.

MCLAREN, P. A vida nas escolas: uma introdução à pedagogia crítica nos fundamentos da educação. 2. ed. Porto Alegre: ARTMED, 1997.

PEIRANO, M. A favor da etnografia. Rio de Janeiro: Relume-Dumará, 1995. 
SANTOS, M. Por uma outra globalização: do pensamento único à consciência universal. 6 . ed. Rio de Janeiro: Record, 2001.

SOARES, J. A violência simbólica no cotidiano escolar: reflexões sobre o corpo da criança na escola. Conexões, Campinas, v. 11, p. 50-74, jul./set. 2013.

SPOSITO, M. Um breve balanço da pesquisa sobre violência escolar no Brasil. Educação e Pesquisa, v. 27, n. 1, p. 87-103, jan./jun. 2001.

ZALUAR, A. Teoria e prática do trabalho de campo: alguns problemas. In: CARDOSO R et al. A aventura antropológica: teoria e pesquisa. Rio de Janeiro: Paz e Terra, 1986. p. 107126.

WOODS, P. La escuela por dentro: la etnografía en la investigación educativa. Barcelona: Paidós, 1998.

Recebido em: 03/09/2018

Revisado em: 05/02/2019

Aprovado em: 18/03/2019

Endereço para correspondência:

gabrielgules@gmail.com

Gabriel Gules Goularte

Universidade Federal do Rio Grande Sul, Escola de Educação Física.

Rua Felizardo, 750

Jardim Botânico

90690-200 - Porto Alegre, RS - Brasil 